\title{
Sleep problems and profiles in attention deficit hyperactivity disorder assessed by the Children Sleep Habits Questionnaire-Abbreviated in Colombia
}

\author{
Juan David Palacio-Ortiz, ${ }^{1,2}$ Sujey Gomez-Cano, 1,2 Daniel Camilo Aguirre-Acevedo3
}

Departamento de Psiquiatría, Facultad de Medicina, Universidad de Antioquia, Medellín, Colombia.

2 Programa de Trastornos del Ánimo, Hospital Universitario San Vicente Fundación, Medellín, Colombia.

3 Instituto de Investigaciones, Facultad de Medicina, Universidad de Antioquia, Medellín, Colombia.

\section{Correspondence:}

Juan David Palacio-Ortiz

Grupo de Investigación en Psiquiatría, Departamento de Psiquiatría, Facultad de Medicina, Universidad de Antioquia

Hospital Universitario San Vicente de Paúl, Calle 64 no. 51 D - 154, Bloque 4, Medellín, Colombia. Mobile: +5731 4615 - 9744

Email: tdahcartagena@gmail.com

Received: 15 July 2018

Accepted: 3 December 2018

\section{Citation:}

Palacio-Ortiz, J. D., Gomez-Cano, S., \& Aguirre-Acevedo, D. C. (2018). Sleep problems and profiles in attention-deficit hyperactivity disorder assessed by the Children Sleep Habits Questionnaire-Abbreviated in Colombia. Salud Mental, 41 (6), 261-269. doi: 10.17711/SM.0185-3325.2018.038

\section{cc) (1) $\$$}

\begin{abstract}
Introduction. Sleep problems are frequent in patients with attention deficit hyperactivity disorder (ADHD), but often underestimated in clinical settings. Objective. To describe the main characteristics of sleep habits in an ADHD outpatient population using the Children Sleep Habits Questionnaire-Abbreviated (CSHQ-A) to compare ADHD groups according to the presence of comorbidity and the presence of current treatment, and to determine sleep profiles by using latent class analysis (LCA). Method. A sample of 228 ADHD patients (Mage $=11.5$ years old, $(I R=9-15)$ were enrolled. ADHD comorbidities and treatments were registered. Parents/caregivers filled out the questionnaire. Participants groups were compared, and LCA was used to classify profiles of similar sleep patterns. Results. The ADHD group with treatment had a higher score in the CSHQ-A than the group without treatment. Four classes emerge: Class 1 only children, males, half with comorbid ADHD, many with treatment, and with many sleep problems (CSHQ-A mean: 25.98). Class 2: mostly adolescents, female, with comorbid anxiety disorder, and who did not show sleep problems (CSHQ-A mean: 12.78). Class 3: only adolescents, males, comorbid with major depressive disorder and CSHQ-A who showed many sleep problems. Class 4 : only children, males, the majority with treatment, with some sleep problems. Discussion and conclusion. In this ADHD sample, patients with psychopharmacological treatment have a greater report of sleep problems by the CSHQ-A compared to those who do not receive treatment.
\end{abstract}

Keywords: Attention deficit disorder hyperactivity, sleep, questionnaires, children, adolescents, treatment.

\section{RESUMEN}

Introducción. Los problemas del sueño son frecuentes en pacientes con trastorno por déficit de atención con hiperactividad (TDAH), pero a menudo se subestiman en la consulta. Objetivo. Describir las principales características de los hábitos de sueño en una población de pacientes ambulatorios con TDAH utilizando el Cuestionario de Hábitos de Sueño de Niños-Abreviado (CSHQ-A), comparar los grupos con TDAH según la presencia de comorbilidad y de tratamiento actual y determinar los perfiles del sueño mediante el análisis de clase latente $(\mathrm{ACL})$. Método. Se recogió una muestra de 228 pacientes con TDAH (edad $M=11.5$ años, $(R I=$ 9 - 15). Los padres / cuidadores completaron el cuestionario. Se compararon los grupos de participantes y se utilizó el ACL para clasificar los perfiles de patrones de sueño similares. Resultados. El grupo con TDAH con tratamiento tuvo una puntuación más alta en CSHQ-A que el grupo sin tratamiento. Surgieron cuatro clases: Clase 1 sólo niños varones, mitad con TDAH comórbido, muchos con tratamiento y con muchos problemas de sueño (media CSHQ-A: 25.98). Clase 2: la mayoría mujeres adolescentes con trastorno de ansiedad comórbido y sin problemas de sueño (CSHQ-A media: 12.78). Clase 3: adolescentes, varones, con depresión comorbida: el CSHQ-A mostró muchos problemas de sueño. Clase 4: sólo niños, hombres, la mayoría con tratamiento, con algunos problemas de sueño. Discusión y conclusión. En esta muestra de TDAH, los pacientes con tratamiento psicofarmacológico tienen un mayor informe de problemas de sueño según CSHQ-A en comparación con aquellos sin tratamiento.

Palabras clave: Trastorno de déficit de atención con hiperactividad, sueño, cuestionarios, niños, adolescentes, tratamiento. 


\section{INTRODUCTION}

Patients with attention deficit hyperactivity disorder (ADHD) have sleep disorders in up to $25 \%-30 \%$ of the cases (Nunes \& Bruni, 2015), or transient alterations in sleep patterns in 48 - 73\% (Barrett, Tracy, \& Glaroli, 2013). Sleep disturbances are frequently reported by both parents and children with ADHD at bedtime or increased night-time awakenings (Mayes, Calhoun, Bixler, \& Al, 2009; Owens, Maxim, Nobile, McGuinn, \& Msall, 2000). Although in some cases it is attributed to the use of stimulants, in many others it is an alteration associated with ADHD per se (Corkum, Moldofsky, Hogg-Johnson, Humphries, \& Tannock, 1999). Sleep problems can have an impact on ADHD and also on learning and impulse control (Sadeh, Gruber, \& Raviv, 2002). For this reason, a routine evaluation of sleep problems in this population is highly recommended. Considering the armamentarium of sleep evaluation, questionnaires can be the best tools in terms of cost-effectiveness.

The Children's Sleep Habits Questionnaire (CSHQ) (Owens, Spirito, \& McGuinn, 2000), is a parent-rated questionnaire validated for school-aged children (4 - 10 years old), but widely used in clinical settings for children and adolescents (2 - 18 years old). The short-form CSHQ includes 33 distinct items grouped into eight subscales: bedtime resistance, sleep-onset delay, sleep duration, sleep anxiety, night-waking, parasomnias, sleep disorders of breathing, and daytime sleepiness. The CSHQ alone is not sufficient for a diagnosis, but it is an instrument that can provide complementary information to the clinical interview. To date there has been a limited number of studies on this topic published in Latin America.

The purpose of this study was to describe the main characteristics of sleep habits in a population that attended outpatient consultation of child and adolescent psychiatry using the CSHQ reported by their parents. Also, to compare ADHD patients according to the presence of comorbidity and/or current treatment. Another objective was to determine some possible sleep profiles by using latent class analysis (LCA). LCA models use patterns of responses on observed categorical variables to classify individuals into latent classes, where in each class there are different response probabilities across items.

\section{METHOD}

A cross-sectional study was conducted from $05 / 02 / 2016$ to 05/10/2018. The sample consisted of patients aged $6-18$ years who were consecutively diagnosed as having ADHD in a clinical setting in Medellin, Colombia, during a 24-month period. ADHD diagnosis was made by a child psychiatrist (20 years of experience). Sample size was calculated based on the total sampling. Patient enrolled in the study met the following criteria: subjects ages between six and 18 years with a current ADHD as primary diagnosis, subjects that assisted with a parent/caregiver who lived at home, and subjects who were attending school. The researcher interviewed the children and parents/caregivers and then filled out the CSHQ-Abbreviated (CSHQ-A) after the parents were being informed of the study and gave their written consent. Subjects were excluded if they had: a documented history in medical record of seizure disorder or notable head injury, neurodegenerative disease, mental retardation (IQ $>70$ on the Wechsler Intelligence Scale for Children IV), or classic autism (DSM-IV-TR). Subjects who were in their holidays were also excluded.

\section{Materials}

The CSHQ-A (NICHD SECCYD-Wisconsin, 2017) was used in this study to assess sleep problems. These questionnaires were attained primarily by a retrospective method with the parents/caregivers recalling on last week sleep patterns, disturbances, or behaviors (e.g., bed time, sleep behavior, waking during the night, morning wake up) (NICHD SECCYD-Wisconsin, 2017). The 22 items of the CSHQ-A are rated on a five-point scale ranging from $4=$ "always" if the sleep behavior occurred seven times in the past week, 3 = "usually" if the behavior occurred five - six times in the past week, 2 = "sometimes" for two to four times that week, $1=$ "rarely" for once a week, and $0=$ "never" for zero times that week. A total score of more than 30 on CSHQ-A was taken as abnormal and indicative of sleep problems (NICHD SECCYD-Wisconsin, 2017). The questionnaire CSHQ-A (NICHD SECCYD-Wisconsin, 2017) was translated into Spanish with doctor Judith Owens written permission; the English back translation was revised afterwards by a native translator. This questionnaire is under its validity process in Colombia.

\section{Procedures}

Patients were ascertained in a University Hospital at Medellin, Colombia. An experienced child psychiatrist interview both parents (caregivers) and patients in order to make the ADHD diagnosis according to the DSM-5 and also psychiatric comorbidities. Data was collected regarding demographic characteristics (subject and family), ADHD presentation either combined (ADHD-C) or inattentive (ADHD-I), psychiatric comorbidities, and current medication (last two months or longer). Clinical medical records were reviewed in order to verify possible exclusion criteria. Parents (or caregivers) were asked to fill out the CSHQ-A and then it was verified to avoid unchecked answers.

The following comorbidity groups were determined: disruptive disorders (oppositional and defiant, intermittent and explosive, and conduct disorders), anxiety disorders 
(separation anxiety, generalized anxiety, social anxiety, obsessive compulsive, posttraumatic disorders), major depression disorder (MDD), learning, language and autism spectrum disorders (specific learning, language and autism spectrum disorders), bipolar spectrum disorders (bipolar and unspecified bipolar disorder), other disorders (low frequency comorbidities were group together such as tics disorders, feeding disorders and enuresis), and without comorbidities (ADHD pure).

Medication groups were determined as follows: stimulants (immediate released methylphenidate, long-acting methylphenidate and OROS), selective norepinephrine reuptake inhibitors (SNRI, such as atomoxetine), selective serotonin reuptake inhibitors (SSRI, such as fluoxetine, sertraline, fluvoxamine), second generation antipsychotics (SGA, such as risperidone, quetiapine, aripiprazole, olanzapine), alfa-adrenergic (clonidine), melatonin, and without medication (medication naive or no medication during the last two months). If a patient was not currently taking a prescribed treatment for any reason, he/she was classified as without treatment in this study. A variable called "medication that can cause insomnia" was arranged to divide the group in those who took stimulants and those who did not, and another variable called "medication that can cause somnolence" to divide the group into those who took any of these medications: SGA, clonidine, and/or melatonin, and those who did not. In this study, only medications that patients were taking before filling out the questionnaire were described. Although a significant percentage of patients had prescribed medications in prior consultations, due to difficulties in the Colombian health system they were not taking them at the time of the study, so they were classified as without treatment. This study was approved by the Ethics Committee Faculty of Medicine, University of Antioquia and Hospital San Vicente Fundación.

\section{Statistical methods}

Participants were classified according to whether they presented ADHD comorbidity and/or prescribed medication. They were described according to their demographic and clinical characteristics, and also by the CSHQ-A result, using median and interquartile range (25th and 75th percentile) in the quantitative variables and frequency and percentage in the categorical variables. Groups were compared using Chi-square test or Fisher exact test, Mann-Whitney U test, and effect size (Austin, 2009; Fritz, Morris, \& Richier, 2012). For non-parametric effect size we assumed a high effect size above .5 , moderate between .3 and .5 , and low under .3 , and a level of significance $p<.05$ (Coolican, 2009; Fritz et al., 2012). Using a linear regression model, the difference was estimated in adjusted means with their respective $95 \%$ confidence interval (CI) between groups: ADHD with comorbidity versus ADHD pure, and between
ADHD with treatment and ADHD without treatment. Those variables that showed significant differences according to the Hosmer-Lemeshow criterion $(p<.25)$, were adjusted (Hosmer \& Lemeshow, 2000). These analyzes were performed in IBM SPSS version 23, and STATA version 14.0.

\section{Sleep habits profile in ADHD}

Latent class analysis (LCA) was used to explore the sleep habits profile according to ADHD presentation, demographic characteristics, comorbidity and/or prescribed medication (Lanza \& Rhoades, 2013). This type of analysis allows to include both quantitative and qualitative variables. In this analysis the following were included: age (children/ adolescents), gender (male/female), socioeconomic status (low/high), parental age, separation (yes/no), ADHD presentation (ADHD-C/ADHD-I), comorbidity (presence/absence), medication (yes/no), and the CSHQ-A total score. This analysis proposes that the sample can be divided into $K$ number of classes. The Latent Gold 3.0 software (Vermunt \& Magidson, 2000) was used to determine the optimal number of classes (profiles). Models were estimated from one class (under the assumption of homogeneity) up to 10 classes (under the assumption of heterogeneity in the sleep habits profiles of $K$ latent class in ADHD). For the selection of the model with $K$ classes, the Bayesian Information Criterion $(B I C)$ was used, so it was selected the best fitting model with the lowest BIC among 10 models (Vermunt \& Magidson, 2002). Here, the conditional probabilities that indicate the chance of having the characteristic according to class membership are shown, or otherwise the equally conditional mean in the quantitative variables. In the same way, the prevalence of each class is shown and for the chosen model the percentage of classification errors and the entropy (pseudo $R^{2}$ that indicates the best fitting model: the closer to one is the better). Entropy refers to how well subjects have been classified into each latent group.

\section{RESULTS}

A total of 228 ADHD patients who attended the outpatient service were evaluated. Thirty-eight subjects were not taken into account because they had some exclusion criteria. The sample consisted of 169 men (74.12\%) and 59 women $(25.8 \%)$, with a median age of 11.5 years of age (IR: 9$15)$, and an average of six grades of schooling (IR: 3-9). Mother's age during pregnancy was 25 years on average. One third of the sample had separated parents. Demographic characteristics according to comorbidities and treatments are showed in Tables 1 and 2. The ADHD-C presentation was the most frequent with $53.5 \%$, followed by ADHD-I with $47.5 \%$. Psychiatric comorbidity was present in two thirds of the sample, and only $37.7 \%$ had some medication 
Table 1

Demographic and Clinical Characteristics according to ADHD comorbidity

\begin{tabular}{|c|c|c|c|c|c|c|}
\hline Gender, $n \%$ & \multicolumn{2}{|c|}{$\begin{array}{c}\text { Pure ADHD } \\
n=86\end{array}$} & \multicolumn{2}{|c|}{$\begin{array}{c}\text { ADHD } \\
\text { with Comorbidity } \\
n=142\end{array}$} & $\frac{\text { Effect Size }}{.18}$ & $\frac{p \text { value }}{.184}$ \\
\hline Female & 18 & $20.9 \%$ & 41 & $28.9 \%$ & & \\
\hline Male & 68 & $79.1 \%$ & 101 & $71.1 \%$ & & \\
\hline Age (years old), median (IR) & 11.0 & $(8-14)$ & 12.0 & $(9-15)$ & .09 & .187 \\
\hline \multicolumn{7}{|l|}{ Age group } \\
\hline $4-12$ year old & 57 & $66.3 \%$ & 83 & $58.5 \%$ & & \\
\hline $13-18$ year old & 29 & $33.7 \%$ & 59 & $41.5 \%$ & .16 & \\
\hline School grades, median (IR) & 5.0 & $(3-8)$ & 6.0 & $(3-9)$ & .04 & .515 \\
\hline School failed grades, median (IR) & .0 & $(0-1)$ & .0 & $(0-1)$ & .10 & .133 \\
\hline Residence area & & & & & .02 & .875 \\
\hline Rural & 22 & $25.6 \%$ & 35 & $24.6 \%$ & & \\
\hline Urban & 64 & $74.4 \%$ & 107 & $75.4 \%$ & & \\
\hline Socioeconomic status & & & & & .09 & .500 \\
\hline High (4,5 and 6) & 19 & $22.1 \%$ & 37 & $26.1 \%$ & & \\
\hline Low $(1,2$ and 3$)$ & 67 & $77.9 \%$ & 105 & $73.9 \%$ & & \\
\hline Fathers age, median (IR) & 42.5 & $(37-45)$ & 43.0 & $(38-46)$ & .13 & .053 \\
\hline Mothers age, median (IR) & 35.0 & $(33-40)$ & 35.0 & $(35-42)$ & .11 & .091 \\
\hline Number of siblings, median (IR) & 1.0 & $(0-1)$ & 1.0 & $(0-1)$ & & .695 \\
\hline Place between siblings, median (IR) & 1.5 & $(1-2)$ & 1.5 & $(1-2)$ & & .969 \\
\hline Mothers age at pregnancy, median (IR) & 24.0 & $(21-28)$ & 25.0 & $(21-30.1)$ & & .332 \\
\hline Parental separation & 29 & $33.7 \%$ & 34 & $23.9 \%$ & .06 & .110 \\
\hline Age at parental separation, median (IR) & 6.0 & $(4-8)$ & 7.3 & $(4-10)$ & .10 & .133 \\
\hline ADHD presentation, $n \%$ & & & & & .67 & $<.001$ \\
\hline Inattentive & 57 & $66.3 \%$ & 49 & $34.5 \%$ & NA & \\
\hline Combined & 29 & $33.7 \%$ & 93 & $65.5 \%$ & & \\
\hline \multicolumn{7}{|l|}{ Comorbidities } \\
\hline Disruptive disorders & & & 66 & $46.5 \%$ & NA & \\
\hline Major depressive disorder & & & 35 & $24.6 \%$ & NA & \\
\hline Learning, language or autism spectrum disorder & & & 36 & $25.4 \%$ & NA & \\
\hline Other comorbidities & & & 20 & $14.1 \%$ & NA & \\
\hline Bipolar spectrum disorder & & & 8 & $5.6 \%$ & NA & \\
\hline Comorbidity number, median (IR) & & & 1.0 & $(1-2)$ & NA & \\
\hline Actually medicated & 26.0 & $30.2 \%$ & 60.0 & $42.3 \%$ & .18 & .070 \\
\hline Medications number, median (IR) & 0 & 1 & 0 & 1 & .12 & .067 \\
\hline
\end{tabular}

Note: $n$ = number; \%: percentage; IR = Interquartile range; $\mathrm{ADHD}=$ Attention deficit hyperactivity disorder; NA = Non-applicable.

at the time of the evaluation. The ADHD-C was associated with a higher frequency of comorbidity $(p<.001)$ and a higher frequency of some treatment $(p<.001)$.

\section{Results of the CSHQ-A}

Questionnaires were filled out mostly by mothers (87.3\%), and the rest were answered by fathers or other caregivers. There were no missing data. Taking into account as sleep problems only those answers with higher scores ("always" $=4$ points), this sample of ADHD presented: "child is restless during sleep" (27.6\%), "child resists going to bed at bedtime" (21.9\%), night awakenings "child wakes up at once during the night" (16.2\%) and waking too early (18.9\%). As for "child falls asleep within 20 minutes after going to bed" ("never" $=4$ points), $8.3 \%$ of the sample had sleep onset delay. The analysis of the CSHQ-A total score and every dimension by groups according to the presence of comorbidity or medication is shown in Table 3 .

The ADHD group with comorbidity had higher scores in the CSHQ-A than the ADHD pure group, especially in the dimension of hypersomnia. After adjusting for gender, socioeconomic status, fathers age, mothers age, ADHD presentation, and comorbidity, the difference is only one point $(95 \% \mathrm{CI}=-4,2)$. Although hypersomnia item had still a significant difference, the effect size was low. The ADHD group with treatment had a higher score in the CSHQ-A than the group without treatment, not only for total score (median: 25 versus 18 points), but also for each dimension studied. After adjusting by gender, age, ADHD presentation, socioeconomic level, age of the father, and age of the mother and comorbidity, the difference was five points 
Table 2

Demographic and clinical characteristics according to prescribed medication

\begin{tabular}{|c|c|c|c|c|c|c|}
\hline Gender & \multicolumn{2}{|c|}{$\begin{array}{l}\text { Without treatment } \\
\quad n=142\end{array}$} & \multicolumn{2}{|c|}{$\begin{array}{l}\text { With treatment } \\
\quad n=86\end{array}$} & $\frac{\text { Effect Size }}{.32}$ & $\frac{p \text { value }}{.024}$ \\
\hline $\begin{array}{l}\text { Female } \\
\text { Male } \\
\text { Age (years old), median (IR) }\end{array}$ & $\begin{array}{l}44 \\
98 \\
11.6\end{array}$ & $\begin{array}{r}31.0 \% \\
69.0 \% \\
(9-15)\end{array}$ & $\begin{array}{l}15 \\
71 \\
11.0\end{array}$ & $\begin{array}{r}17.4 \% \\
82.6 \% \\
(8-15)\end{array}$ & .05 & .407 \\
\hline \multicolumn{7}{|l|}{ Age group } \\
\hline $\begin{array}{l}4-12 \text { year old } \\
13-18 \text { year old } \\
\text { School grades, median (IR) } \\
\text { School failed grades, median (IR) }\end{array}$ & $\begin{array}{r}83 \\
59 \\
5.5 \\
.0\end{array}$ & $\begin{array}{l}58.5 \% \\
41.5 \% \\
(3-8) \\
(0-1)\end{array}$ & $\begin{array}{r}57 \\
29 \\
5.0 \\
.0\end{array}$ & $\begin{array}{l}66.3 \% \\
33.7 \% \\
(3-9) \\
(0-1)\end{array}$ & $\begin{array}{l}.04 \\
.11\end{array}$ & $\begin{array}{l}.559 \\
.104\end{array}$ \\
\hline $\begin{array}{l}\text { Residence area } \\
\text { Rural } \\
\text { Urban }\end{array}$ & $\begin{array}{r}37 \\
105\end{array}$ & $\begin{array}{l}26.1 \% \\
73.9 \%\end{array}$ & $\begin{array}{l}20 \\
66\end{array}$ & $\begin{array}{c}.07 \\
23.3 \% \\
76.7 \%\end{array}$ & .636 & \\
\hline $\begin{array}{l}\text { Socioeconomic status } \\
\text { High }(4,5 \text { and } 6) \\
\text { Low }(1,2 \text { and } 3) \\
\text { Fathers age, median (IR) } \\
\text { Mothers age, median (IR) } \\
\text { Number of siblings, median (IR) } \\
\text { Place between siblings, median (IR) } \\
\text { Mothers age at pregnancy, median (IR) } \\
\text { Parental Separation } \\
\text { Age at parental separation, median (IR) }\end{array}$ & $\begin{array}{c}36 \\
106 \\
43.0 \\
35.0 \\
1.0 \\
1.0 \\
23.2 \\
41 \\
8.0\end{array}$ & $\begin{array}{c}25.4 \% \\
74.6 \% \\
(39-45) \\
(35-39) \\
(0-1) \\
(1-2) \\
(20.0-27.1) \\
28.9 \% \\
(4-10.1)\end{array}$ & $\begin{array}{l}20 \\
66 \\
42.4 \\
39.5 \\
1 \\
1 \\
28.5 \\
22 \\
6.0\end{array}$ & $\begin{array}{c}.05 \\
23.3 \% \\
76.7 \% \\
(36-48) \\
(34-45) \\
(0-1) \\
(1-2) \\
(23-32) \\
25.6 \% \\
(4-6.7)\end{array}$ & $\begin{array}{l}.01 \\
.23 \\
.07 \\
.04 \\
.28 \\
.28 \\
.10\end{array}$ & $\begin{array}{r}.847 \\
.001 \\
.261 \\
.547 \\
<.001 \\
.117\end{array}$ \\
\hline $\begin{array}{l}\text { ADHD presentation, } n \% \\
\text { Inattentive } \\
\text { Combined }\end{array}$ & $\begin{array}{l}78 \\
64\end{array}$ & $\begin{array}{l}54.9 \% \\
45.1 \%\end{array}$ & $\begin{array}{l}28 \\
58\end{array}$ & $\begin{array}{l}32.6 \% \\
67.4 \%\end{array}$ & .46 & .001 \\
\hline \multicolumn{7}{|l|}{ Comorbidities } \\
\hline $\begin{array}{l}\text { Disruptive disorders } \\
\text { Major depressive disorder } \\
\text { Learning, language or autism spectrum disorder } \\
\text { Other comorbidities } \\
\text { Bipolar spectrum disorder } \\
\text { Disruptive disorders }\end{array}$ & $\begin{array}{r}35 \\
31 \\
18 \\
18 \\
12 \\
3\end{array}$ & $\begin{array}{r}24.6 \% \\
21.8 \% \\
12.7 \% \\
12.7 \% \\
8.5 \% \\
2.1 \%\end{array}$ & $\begin{array}{r}31 \\
13 \\
17 \\
18 \\
8 \\
5\end{array}$ & $\begin{array}{r}36.0 \% \\
15.1 \% \\
19.8 \% \\
20.9 \% \\
9.3 \% \\
5.8 \%\end{array}$ & $\begin{array}{l}.25 \\
.17 \\
.19 \\
.22 \\
.03 \\
.19\end{array}$ & $\begin{array}{l}.066 \\
.213 \\
.15 \\
.098 \\
.826 \\
.141\end{array}$ \\
\hline Comorbidity number, median (IR) & 1 & $(0-1)$ & 1 & $(0-2)$ & .97 & $<.001$ \\
\hline
\end{tabular}

Note: $n=$ number; $\%$ = percentage; $\mathrm{IR}=$ Interquartile range; $\mathrm{ADHD}=$ Attention deficit hyperactivity disorder.

Table 3

CSHQ-A Dimension according to presence or absence of comorbidity and prescribed medication

\begin{tabular}{lcccccccc}
\hline & \multicolumn{2}{l}{ Without comorbidity $n=86$} & & \multicolumn{2}{l}{ With comorbidity $n=142$} & & \\
\cline { 2 - 3 } Comorbidity & Median & IR & & Median & IR & Effect Size & $p$ value \\
\hline CSHQ-A total score & 19.5 & $(14-28)$ & & 22.0 & $(13-29)$ & -.03 & .656 \\
Sleep resistance & 1.0 & $(1-4)$ & & 1.0 & $(1-4)$ & -.03 & .646 \\
Sleep Onset Delay & 1.0 & $(0-2)$ & & 2.0 & $(1-2)$ & -.10 & .134 \\
Regular sleep duration & 1.0 & $(0-1)$ & & 1.0 & $(0-1)$ & -.02 & .814 \\
Anxiety to get to sleep & 4.0 & $(1-8)$ & & 3.0 & $(1-9)$ & .00 & .958 \\
Nocturnal awakenings & 3.0 & $(1-6)$ & & 3.0 & $(1-5)$ & -.03 & .603 \\
Parasomnias & 6.0 & $(3-8)$ & & 6.0 & $(2-9)$ & -.03 & .614 \\
Respiratory & .0 & $(0-2)$ & & .0 & $(0-2)$ & -.01 & .857 \\
Hypersomnia & 4.0 & $(3-6)$ & 5.0 & $(3-7)$ & -.14 & .034 \\
\hline
\end{tabular}

\begin{tabular}{lccccccc}
\hline & \multicolumn{2}{l}{ Without medication $n=142$} & & \multicolumn{2}{l}{ With medication $n=86$} & & \\
\cline { 2 - 3 } Prescribed medication & Median & IR & & Median & IR & Effect Size & $p$ value \\
\hline CSHQ - A total score & 18.0 & $(11-26)$ & & 25.0 & $(17 .-32)$ & -.29 & $<.001$ \\
Sleep resistance & 1.0 & $(0-3)$ & & 2.0 & $(1-14)$ & -.16 & .015 \\
Sleep Onset Delay & 1.0 & $(0-2)$ & & 2.0 & $(1-2)$ & -.17 & .008 \\
Regular sleep duration & 1.0 & $(0-1)$ & & 1.0 & $(0-2)$ & -.07 & .285 \\
Anxiety to get to sleep & 3.0 & $(0-8)$ & & 5.0 & $(2-9)$ & -.17 & .010 \\
Nocturnal awakenings & 2.0 & $(1-5)$ & & 4.0 & $(2-7)$ & -.24 & .000 \\
Parasomnias & 5.0 & $(2-8)$ & & 7.0 & $(4-10)$ & -.22 & .001 \\
Respiratory & .0 & $(0-1)$ & & .0 & $(0-2)$ & -.19 & .004 \\
Hypersomnia & 4.0 & $(3-6)$ & 5.0 & $(4-8)$ & -.18 & .006 \\
\hline
\end{tabular}

Note: CSHQ-A = Children Sleep Habits Questionnaire Abbreviated; IR = Interquartile range; $n=$ number; $\%=$ percentage; $\mathrm{ADHD}=$ Attention deficit hyperactivity disorder. 
Table 4

Selection of $K$ classes model. Latent classes analysis of sleep profile in $A D H D$ patients

\begin{tabular}{|c|c|c|c|c|c|}
\hline Model & LL & BIC & Npar & $\begin{array}{l}\text { Classifica- } \\
\text { tion errors }\end{array}$ & Entropy \\
\hline 1-Class & -3930.5567 & 8170.5861 & 57 & .0000 & 1.0000 \\
\hline 2-Classs & -3775.8677 & 7942.6484 & 72 & .0068 & .9820 \\
\hline 3-Classs & -3625.892 & 7724.137 & 87 & .0182 & .9520 \\
\hline 4-Classs & -3563.6682 & 7681.1297 & 102 & .0399 & .9190 \\
\hline 5-Classs & -3531.4319 & 7698.0972 & 117 & .0585 & .9007 \\
\hline 6-Classs & -3502.896 & 7722.4656 & 132 & .0576 & .9089 \\
\hline 7-Classs & -3479.44 & 7756.9938 & 147 & .0669 & .9021 \\
\hline 8-Classs & -3453.0621 & 7785.6781 & 162 & .0615 & .9203 \\
\hline 9-Classs & -3430.0184 & 7821.031 & 177 & .0653 & .9103 \\
\hline 10-Classs & -3405.1441 & 7852.7225 & 192 & .0540 & .9287 \\
\hline
\end{tabular}

Note: $A D H D=$ Attention deficit hyperactivity disorder; $L L=$ logarithm of likelihood; $\mathrm{BIC}=$ Bayesian information index; npar $=$ number of parameters in the model.

$(95 \% \mathrm{CI}=2,8)$. In all dimensions there were significant differences with moderate to low effect sizes, except sleep duration. (Table 3)

The latent classes analysis (LCA) allowed to identify four groups. Information regarding the test criteria to find the best number of latent classes can be found in Table 4 . The model of four classes for the sleep profile in ADHD was selected, with these properties: Log-likelihood -3563.6682 , BIC: 7681.1297, number of parameters in model 102, classification errors .0399 , and entropy of .9190 . Table 5 presents the conditional probability for each characteristic according to de class, and Figure 1 presents the frequency of comorbidity in each class. Class 1 (34\%) only children, males with young parents, most with ADHD-C (57\%), half with comorbid ADHD (especially disruptive learning or language disorders) many with treatment $(41 \%)$, and the CSHQ-A showed many sleep problems (mean: 25.98).Class 2: mostly adolescents (64\%), female, ADHD-I (66\%), comorbid ADHD (especially with anxiety disorder) without treatment and did no show sleep problems (mean: 12.78). Class 3: only adolescents, males, ADHD-C (64\%), comorbid ADHD (66\%), (especially with MDD), half with treatment, and CSHQ-A showed many sleep problems. Class 4: only children, males, half of the ADHD-C group, the majority with comorbid ADHD (especially disruptive learning or language disorders), older parents (not separated), the majority with treatment (60\%), and CSHQ-A showed some sleep problems (Table 5). Regarding the presence of comorbidity with anxiety disorders or MDD there were statistically significant differences for class 2 and class $3(p<.001$ and $p=.007$ respectively) (Figure 1).

\section{DISCUSSION AND CONCLUSION}

Sleep problems have been studied in children and adolescents with ADHD using different techniques from the most

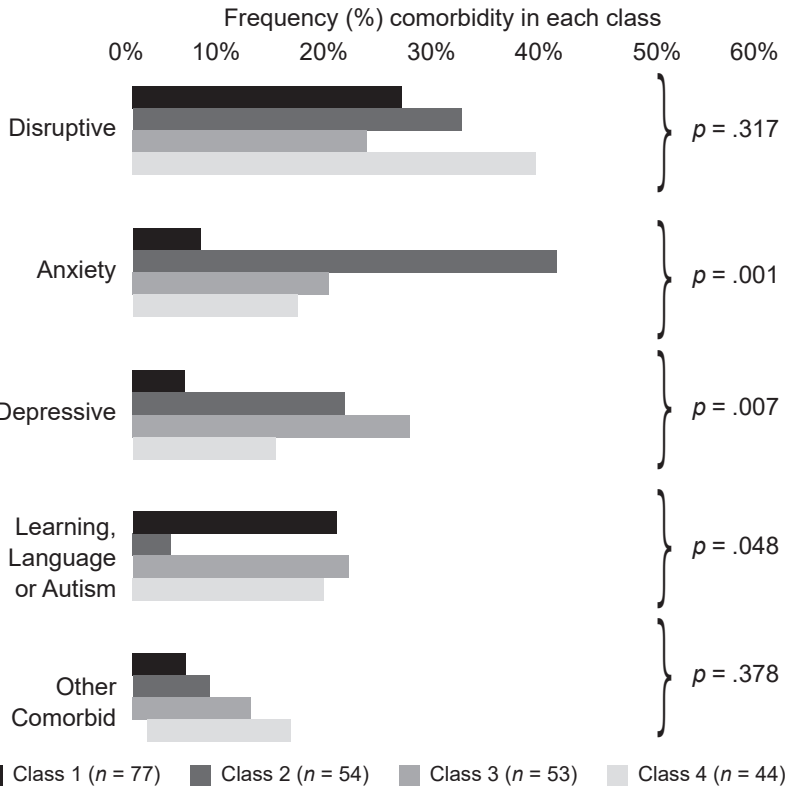

Figure 1. Frequency of comorbidities according to the 4 classes in ADHD.

Note: $\mathrm{ADHD}=$ Attention Deficit Hyperactivity Disorder.

to the least invasive. The purpose of this study was to describe the sleep profile of patients attending an outpatient service, using the parental report about last week patients' sleep. The abbreviated questionnaire was used, which is a simple and easy way to collect data in the clinical setting. The CSHQ-A pointed out some sleep problems in this sample of ADHD children and adolescents. Our results showed

Table 5

Sleep profile, comorbidity, medication in a sample of ADHD. Conditional probabilities of the characteristics according to the class. Results for the model of 4 classes according to the latent classes analysis

\begin{tabular}{lrrrr}
\hline Characteristics & Class 1 & Class 2 & Class 3 & Class 4 \\
\hline Age group & & & & \\
4 - 12 years old & .99 & .36 & .00 & .96 \\
13 - 18 years old & .01 & .64 & 1.00 & .04 \\
Male gender & .81 & .52 & .76 & .86 \\
School grades, median (IR) & 2.99 & 7.32 & 9.03 & 4.30 \\
Low SES (1,2 and 3) & .85 & .72 & .76 & .63 \\
Fathers age, (years) & 35.83 & 43.89 & 44.79 & 48.02 \\
Mothers age (years) & 32.58 & 35.00 & 42.68 & 42.86 \\
Parental separation & .31 & .35 & .33 & .09 \\
ADHD presentation & & & & \\
Inattentive & .43 & .66 & .36 & .43 \\
Combine & .57 & .34 & .64 & .57 \\
Comorbidity & .51 & .67 & .66 & .72 \\
Prescribed medication & .41 & .04 & .48 & .59 \\
CSHQ-A total score, median & 25.98 & 12.78 & 24.28 & 20.10 \\
Class prevalence (\%) & $34 \%$ & $23 \%$ & $23 \%$ & $23 \%$ \\
\hline Note: SES = Socioeconomic Status; \% $\%$ percentage, ADHD; CSHQ-A \\
Children Sleep Habits Questionnaire Abbreviated; ADHD = Attention deficit \\
hyperactivity disorder.
\end{tabular}


that the ADHD group with any treatment had a higher score in the CSHQ-A than the group without treatment. We also found four groups accordingly with the LCA.

The CSHQ-A allowed to appreciate that there are frequent alterations of sleep in ADHD. Some sleep problems found in this sample had been described by other authors (Corkum, Tannock, Moldofsky, Hogg-Johnson, \& Humphries, 2001; Owens, Maxim, et al., 2000; Ring et al., 1998). We found almost one third of the sample with resistance for bed time sleep behaviors such as nocturnal awakenings and restlessness during sleep were prevalent, waking too early was presented in a fifth of the sample, and finally prolonged sleep onset duration was found in about $8 \%$. It is worth to mention that this is a sample collected in an outpatient service, and diagnoses were made by a clinician, but neither diagnoses of ADHD nor of sleep disorders were evaluated through a structured interview. Furthermore, only the CSHQ-A responses were used as a sleep parameter. In spite of those limitations the present findings were analyzed according to ADHD comorbidity and treatment. ADHD comorbidity could be associated with more sleep problems (Alfano, Beidel, Turner, \& Lewin, 2006; Armitage et al., 2000; Ivanenko, Crabtree, \& Gozal, 2004; Sadeh et al., 2002) According to our findings, the relationship between psychiatric comorbid ADHD and sleep problems was scarce and it was only present for the case of hypersomnia (with a low effect size).

The ADHD with treatment group had a higher CSHQ-A total score than those without treatment (median: 25 versus 18 points). Each dimension studied showed also differences. These findings have been suggested by other authors (Cortese, Konofal, Yareman, Mouren, \& Lecendreux, 2006; Konofal, Lecendreux, Bouvard, \& Mouren-Simeoni, 2001; Lecendreux, Konofal, Bouvard, Falissard, \& Mouren-Simeoni, 2000; Owens, Maxim, et al., 2000), although they have used different methodologies and in some cases control groups. In the CSHQ-A total score medians a five-point difference was also found $(95 \% \mathrm{CI}=2,8)$, even after adjusting for gender, age, ADHD presentation, socioeconomic status, parental age and comorbidity. Nocturnal awakenings, hypersomnia, and sleep onset delay were the most striking dimensions according to the analysis made of comparison between groups, but almost all dimensions showed significant differences with low to moderate effect sizes.

A discussion regarding the role of ADHD and/or medications in sleep problems should be held. On the one hand, the ADHD with treatment group was represented mostly by males with ADHD-C, and with a greater number of comorbidities, especially ODD and MDD. It could be postulated that this group is overrepresented with a more severe form of ADHD, and probably sleep problems are more prevalent and in accordance to the ADHD severity. But it has to be considered with caution because severity was not measured, and there were some patients that could have not taken medications for different reasons. On the other hand, regarding the role of medications in this sample, it should be noticed that this ADHD group was not only in treatment with stimulants, but also with other medications that can cause somnolence. Hypersomnia, sleep onset delay (Barrett et al., 2013; Nunes \& Bruni, 2015), fragmented sleep, and nocturnal awakenings have been studied and tried to explain as a result of ADHD or medications, or both (Ball, Tiernan, Janusz, \& Furr, 1997; Kent, Blader, Koplewicz, Abikoff, \& Foley, 1995; Stein, 1999; Tirosh, Sadeh, Munvez, \& Lavie, 1993). Medications can affect sleep in different ways. Although stimulants cause insomnia as an adverse effect, some others have reported somnolence as well (Charach, Ickowicz, \& Schachar, 2004; Galand, Tirpp, \& Taylor, 2010; Kent et al., 1995; Tirosh et al., 1993). The same is also true for atomoxetine (Kratochvilet al., 2006). Some authors have even pointed out that stimulants can reduce restlessness and improve sleep in these patients (Kooij, Middlekoop, van Glis, \& Buitelaar, 2001).

We found that there is greater presentation of nocturnal awakenings in those who take any type of medication, but when analyzing this variable in the group of those taking stimulants, a lower score was found than those who did not. Our analyzes allow us to realize that either nocturnal awakenings or insomnia cannot be attributed to stimulants in this population, and it can be explained more for ADHD itself. The same is also true for medications such as SGA. Cortese et al. (2006) examined 16 studies of children with ADHD who were not medicated, and found out higher rates of bedtime resistance, sleep onset difficulties, night awakenings, and daytime sleepiness than non-ADHD controls according to parent reports (Cortese, Faraone, Konofal, \& Lecendreux, 2009). This supports the notion of the role of ADHD in sleep problems.

An alternative analysis in this ADHD sample identified four classes according to sleep. Two classes presented a greater number of sleep problems as indicated by the CSHQ-A total score: class 1, represented by male with young parents, and class 3 with male, plus ADHD-C, and comorbidity, especially with MDD. Meanwhile, class 2 was striking because of its low index of sleep problems, represented by adolescent women with ADHD-I, and no treatment. While we cannot generalize these findings to other clinical samples, it is interesting to consider that sleep profile could help to elucidate the relationship between ADHD and sleep. A study on sleep phenotypes described five profiles in patients with ADHD, which points out to the importance of recognizing different needs in each patient. However, it was a study oriented more to sleep disorders than to the ADHD characteristics (Miano, Parisi, \& Villa, 2012).

Although the analysis by groups of ADHDs according to comorbidity did not indicate a relationship with sleep problems, in the LCA a possible relationship can be established. Classes 1, 3, and 4 have the highest scores on the 
scale. These are the classes that present more ADHD-C and ADHD comorbidity, especially with disruptive disorder and MDD. The relationship between these disorders and sleep problems has been supported by some authors (Armitage et al., 2000; Cortese et al., 2006; Ivanenko et al., 2004; Sadeh et al., 2002). Class 2 has a high comorbidity with anxiety disorders but had few sleep problems. This could be explained by a higher ADHD-I proportion and no subjects with treatment in this class. Although some authors suggest no relationship between sleep problems and ADHD presentation (LeBourgeois, Avis, Mixon, Olmi, \& Harsh, 2004), others had found more fragmented sleep (Ramos-Platon, Vela-Bueno, Espinar-Sierra, \& Kales, 1990), and more sleep changes in ADHD-C (Dickerson-Mayes et al., 2009; Lecendreux et al., 2000; Mayes et al., 2009). Some studies had suggested that stimulants can affect the sleep profile in ADHD (Kent et al., 1995; Tirosh et al., 1993), and Class 2 subjects were under no treatment.

Future studies about sleep and ADHD should consider a control group, either from the community or in the outpatient service, in order to determine if there is an increased risk of sleep problems in subjects with ADHD, and also if our findings on sleep profiles for LCA are replicable.

\section{Limitations}

The CSHQ-A is under the process of validation in Colombia, and there are still no reference scores in the population. The instrument is used worldwide in children between four and 10 years of age but to a lesser extent in adolescents. Adolescents may have different sleep problems than children, and it has to be considered that parents identify less adolescents' sleep patterns. For this reason, for further studies we suggest to use a scale of adolescent sleep self-report in addition to the parent questionnaire to achieve a better description.

Some study limitations regarding the LCA are worth mentioning. First, the number of parameters of the resulting model was 102 , that means 2.23 participants per parameter. Although the required sample size depends on several aspects, rule of thumb is at least five participants per parameter (Gorsuch, 1983), so it is required to reproduce the model in a larger sample. Second, other classes could be obtained if the CSHQ-A dimensions are used instead of the total score. Finally, instead of using the comorbidity variable (presence/absence), each comorbidity could be included in the latent model class. The same is also true for the case of medications. This was not done because it would increase the number of model parameters. Therefore, additional studies with larger sample sizes are required. Finally, these results cannot be generalized to other populations.

In this sample of children and adolescents with ADHD, the ADHD-C presentation was associated with a higher frequency of comorbidity. These subjects were more likely to be in psychopharmacological treatment and have a greater report of sleep problems by the CSHQ-A in most dimensions compared to those who do not receive treatment. Subjects without comorbidity had fewer sleep problems than those with comorbid ADHD. Through the latent classes model, ADHD groups that present more sleep problems were identified.

\section{Funding}

None.

\section{Conflict of interests}

The authors declare they have no conflict of interests.

\section{Acknowledgment}

All families who participated in the study.

Research Group in Psychiatry (Grupo de Investigación en Psiquiatría-GIPSI).

Hospital Universitario San Vicente Fundacion.

Facultad de Medicina de la Universidad de Antioquia.

\section{REFERENCES}

Alfano, C., Beidel, D., Turner, S., \& Lewin, D. (2006). Preliminary evidence for sleep complaints among children referred for anxiety. Sleep medicine, 7(6), 467-473.

Armitage, R., Emslie, G. J., Hoffmann, R. F., Weinberg, W. A., Kowatch, R. A., Rintelmann, J., \& Rush, A. J. (2000). Ultradian rhythms and temporal coherence in sleep EEG in depressed children and adolescents. Biological Psychiatry, 47(4), $338-350$.

Austin, P. (2009). Using the standardized difference to compare the prevalence of a binary variable between two groups in observational research. Communications in Statistics-Simulation and Computation, 38(6), 1228-1234.

Ball, J., Tiernan, M., Janusz, J., \& Furr, A. (1997). Sleep patterns among children with attention-deficit hyperactivity disorder: A reexamination of parent perceptions. Journal of Pediatric Psychology, 22(3), 389-398.

Barrett, J., Tracy, D., \& Glaroli, G. (2013). To sleep or not to sleep: a systematic review of the literature of pharmacological treatments of insomnia in children and adolescents with attention-deficit/hyperactivity disorder. Journal of child and adolescent psychopharmacology, 23(10), 640-647. doi: 10.1089/cap.2013.0059

Charach, A., Ickowicz, A., \& Schachar, R. (2004). Stimulant treatment over five years: adherence, effectiveness, and adverse effects. Journal of the American Academy of Child \& Adolescent Psychiatry, 43(5), 559-567.

Coolican, H. (2009). Research methods and statistics in psychology. United Kingdom: Hooder.

Corkum, P., Moldofsky, H., Hogg-Johnson, S., Humphries, T., \& Tannock, R. (1999). Sleep problems in children with attention-deficit/hyperactivity disorder: impact of subtype, comorbidity, and stimulant medication. Journal of the American Academy of Child \& Adolescent Psychiatry, 38(10), 1285-1293.

Corkum, P., Tannock, R., Moldofsky, H., Hogg-Johnson, S., \& Humphries, T. (2001). Actigraphy and parental ratings of sleep in children with attention-deficit/hyperactivity disorder (ADHD). Sleep, 24(3), 303-312.

Cortese, S., Faraone, S. V., Konofal, E., \& Lecendreux, M. (2009). Sleep in children with attention-deficit/hyperactivity disorder: meta- analysis of subjective and objective studies. Journal of the American Academy of Child \& Adolescent Psychiatry, 48(9), 894-908.

Cortese, S., Konofal, E., Yareman, N., Mouren, M., \& Lecendreux, M. (2006). Sleep and alertness in children with attention-deficit/hyperactivity disorder: A systematic review of the literature. Sleep, 29(4), 504-511.

Dickerson-Mayes, S. D., Calhoun, S. L., Bixler, E. O., Vgontzas, A. N., Mahr, F., Hillwig-Garcia, J., ... \& Parvin, M. (2009). ADHD Subtypes and Comorbid Anxiety, Depression, and Oppositional-Defiant Disorder: Differences in Sleep 
Problems. Journal of Pediatric Psychology, 34(3), 328-337, doi: 10.1093/jpepsy/jsn083

Fritz, C., Morris, P., \& Richier, J. (2012). Effect size estimates: Current use, calculations, and interpretation. Journal of Experimental Psychology General, 141(1), 2.

Galand, B., Tirpp, E., \& Taylor, B. (2010). The sleep of children with attention deficit hyperactivity disorder on and off methylphenidate: a matched case-control study. Journal of Sleep Research, 19(2), 366-373.

Gorsuch, R. (1983). Factor Analysis. Journal of Psychiatry, 126, 237-240.

Hosmer, D. \& Lemeshow, S. (2000). Applied Logistic Regression. New York: Wiley.

Ivanenko, A., Crabtree, V., \& Gozal, D. (2004). Sleep in children with psychiatric disorders. Pediatric Clinics of North America, 51(1), 51-68.

Kent, J., Blader, J., Koplewicz, H., Abikoff, H., \& Foley, C. (1995). Effects of late-afternoon methylphenidate administration on behavior and sleep in attention-deficit hyperactivity disorder. Pediatrics, 96(2), 320-325.

Konofal, E., Lecendreux, M., Bouvard, M., \& Mouren-Simeoni, M. (2001). High levels of nocturnal activity in children with attention-deficit hyperactivity disorder: A video analysis. Psychiatry and Clinical Neurosciences, 55(22), 97-103.

Kooij, J., Middlekoop, H., van Glis, K., \& Buitelaar, J. (2001). The effect of stimulants on nocturnal motor activity and sleep quality in adults with ADHD: an open-label case-control study. The Journal of clinical psychiatry, 62(12), 952-956.

Kratochvil, C. J., Wilens, T. E., Greenhill, L. L., Gao, H., Baker, K. D., Feldman, P. D., \& Gelowitz, D. L. (2006). Effects of long-term atomoxetine treatment for young children with attention-deficit/hyperactivity disorder. Journal of the American Academy of Child \& Adolescent Psychiatry, 45(8), 919-927.

Lanza, S. \& Rhoades, B. (2013). Latent class analysis: an alternative perspective on subgroup analysis in prevention and treatment. Prevention Science, 14(2), 157-168.

LeBourgeois, M., Avis, K., Mixon, M., Olmi, J., \& Harsh, J. (2004). Snoring, sleep quality, and sleepiness across attention-deficit/hyperactivity disorder subtypes. Sleep, 27(3), 520-525.

Lecendreux, M., Konofal, E., Bouvard, M., Falissard, B., \& Mouren-Simeoni, M. (2000). Sleep and alertness in children with ADHD. Journal of Child Psychiatry, 41(6), 803-812.

Mayes, S., Calhoun, S., Bixler, E., \& Al., E. (2009). ADHD subtypes and comorbid anxiety, depression, and oppositional-defiant disorder: differences in sleep problems. Journal of pediatric psychology, 34(3), 328-337.
Miano, S., Parisi, P., \& Villa, M. (2012). The sleep phenotypes of attention deficit hyperactivity disorder: the role of arousal during sleep and implications for treatment. Medical Hypotheses, 79(2), 147-153. doi: 10.1016/j.mehy.2012.04.020

NICHD SECCYD-Wisconsin. (2017). Children's Sleep Habits Questionnaire (Abbreviated). The National Institute of Child Health and Development (NICHD) Study of Early Child Care and Youth Development (SECCYD). Retrieved from: http://www.education.uci.edu/childcare/pdf/i

Nunes, M. \& Bruni, O. (2015). Insomnia in childhood and adolescence: clinical aspects, diagnosis, and therapeutic approach. Jornal de Pediatria, 91(6), S26-S35.

Owens, J., Maxim, R., Nobile, C., McGuinn, M., \& Msall, M. (2000). Parental and Self-report of Sleep in Children With Attention-Deficit/Hyperactivity Disorder. Archives of pediatrics \& adolescent medicine, 154(6), 549-555.

Owens, J., Spirito, A., \& McGuinn, M. (2000). The Children's Sleep Habits Questionnaire (CSHQ): Psychometric properties of a survey instrument for schoolaged children. Sleep, 23(8), 1043-1051.

Ramos-Platon, M., Vela-Bueno, A., Espinar-Sierra, J., \& Kales, S. (1990). Hypnopolygraphic alternations in attention deficit disorder (ADD) children. International Journal of Neuroscience, 53(2-4), 87-101.

Ring, A., Stein, D., Barak, Y., Teicher, A., Hadjez, J., Elizur, A., \& Weizman, A. (1998). Sleep disturbances in children with attention-deficit/hyperactivity disorder: A comparative study. Journal of Learning Disabilities, 31(6), 572-578.

Sadeh, A., Gruber, R., \& Raviv, A. (2002). Sleep, neurobehavioral functioning, and behavior problems in school-age children. Child development, 73(2), 405-417.

Stein, M. (1999). Unravelling sleep problems in treated and untreated children with ADHD. Journal of Child and Adolescent Psychopharmacology, 9(3), 157-168.

Tirosh, E., Sadeh, A., Munvez, R., \& Lavie, P. (1993). Effects of methylphenidate on sleep in children with attention-deficit hyperactivity disorder: an activity monitor study. American Journal of Diseases of Children, 147(12), 1313-1315.

Vermunt, J. \& Magidson, J. (2002). Latent class cluster analysis. In J. Hagenaars \& A. McCutcheon (Eds.), Applied latent class analysis (pp. 89-106). Cambriddge,: Cambridge University Press.

Vermunt, J. \& Magidson, J. (2000). Latent GOLD User's Guide. Belmont: Statistical Innovations. 